Afiasi: Jurnal Kesehatan Masyarakat, Vol. 4, No. 2, Agustus 2019:41-46

ISSN Print : :2442-5885

Journal homepage: http://afiasi.unwir.ac.id

ISSN Online : 2622-3392

\title{
Hubungan Konsumsi Fast Food dengan Status Gizi Siswa di SMP Negeri 1 Limboto Barat
}

\author{
Relationship of Fast Food Consumption with Student Nutrition Status At SMP 1 West Limboto
}

\begin{abstract}
Abstrak
Fast food merupakan jenis makanan yang dikemas, mudah disajikan, praktis, atau diolah dengan cara sederhana. Fast food biasanya berupa lauk pauk dalam kemasan, mie instan, nugget, dan corn flake. Penelitian ini bertujuan Untuk mengetahui hubungan konsusmsi fast food dengan status gizi pada siswa di SMPN 1 Limboto Barat. Jenis penelitian suvey analitik dengan rancangan Cross Sectional Study dengan tujuan mengetahui hubungan konsumsi fast food dengan status gizi pada siswa. Sampel pada penelitian ini sebanyak 79 siswa dengan pengumpulan data mengunakan lembar Kowsioner. Hasil penelitian ini menunjukan bahwa ada hubungan konsumsi fast food dengan status gizi tidak normal siswa di SMPN 1 Limboto Barat diperoleh nilai dengan nilai $p(0,000)<0,05$. Ditemukan ada hubungan antara Porsi konsumsi Fast Food Dengan status Gizi tidak normal Di SMPN 1 Limboto barat dengan nilai $p(0,000)<0,05$. Ditemukan tidak ada hubungan antara Frekuensi konsumsi Fast Food Dengan status Gizi tidak normal di SMPN 1 Limboto Barat dengan nilai $p(0,833)>0,05$. Diharapkan kepada siswa agar lebih memperhatikan komsusmsi makanannya dengan mengetahui bahwa dari komsumsi fast food yang berlebihan tidaklah baik untuk kesehatan, dan lebih cerdas dalam memilih makanan yang akan dikonsumsi.
\end{abstract}

Herman Hatta

Program Studi Ilmu Gizi, Universitas Gorontalo

email : hattaherman.1988@gmail.com

\section{Pendahuluan}

Kehadiran fast food dalam industri makanan di Indonesia mempengaruhi pola makan. Selain dari pola makan, remaja masa kini jarang melakukan aktivitas fisik seperti berolahraga. Kesadaran yang seperti inilah yang perlu ditumbuhkan pada remaja masa kini, supaya mereka dapat terhindar dari berbagai penyakit yang tidak diharapkan.Pada umumnya menu fast food mengandung lebih tinggi kalori, garam dan lemak termasuk kolesterol, dan menu tipe western umumnya hanya sedikit mengandung serat ${ }^{1}$.

Menurut WHO, remaja merupakan penduduk dalam rentang usia 10-19 tahun, menurut peraturan Menteri Kesehatan RI No.25 tahun 2014 remaja adalah penduduk dalam
Kata Kunci : Jenis Fast Food, Porsi Fast Food, Frekuensi Fast Food

Abstract

Fast food is a type of food that is packaged, easily served, practical, or processed in a simple way. Fast food is usually in the form of side dishes in packaging, instant noodles, nuggets, and corn flakes. This study aims to determine the relationship of fast food consumption with nutritional status in students at West Limboto 1 Middle School. This type of analytic survey research with Cross Sectional Study design with the aim of knowing the relationship of fast food consumption with nutritional status in students. Samples in this study were 79 students with data collection using questionnaires. The results of this study indicate that there is a relationship between fast food consumption and the abnormal nutritional status of students at SMPN 1 West Limboto obtained a value of $p$ $(0,000)<0.05$. It is expected that students pay more attention to their food consumption by knowing that excessive consumption of fast food is not good for health, and is smarter in choosing foods to consume.

Keywords : Types of Fast Food, Fast food portions, Fast Food Frequency

rentan usia 10-18 tahun dan menurut Badan Kependudukan dan Keluarga Berencana (BKKBN) rentang usia remaja adalah 10-24 tahun dan belum menikah. Di dunia diperkirakan kelompok remaja berjumlah 1,2 Milyar atau $18 \%$ dari jumlah penduduk dunia. Berdasarkan proyeksi penduduk pada tahun 2015 menunjukan bahwa jumlah remaja (usia 10-24 tahun) indonesia mencapai lebih dari 66,0 juta atau $25 \%$ dari jumlah Penduduk Indonesia 255 juta. $^{2}$

Masa remaja merupakan masa transisi perkembangan yaitu masa kanak-kanak dan dewasa yang pada umumnya dimulai pada usia 12 atau 13 tahun dan berakhir pada usia akhir belasan tahun atau awal dua puluhan. ${ }^{3}$ 
Remaja sering mengonsumsi makanan siap saji karena kesibukan orang tua, terutama ibu yang tidak sempat menyiapkan makanan di

rumah, sehingga makanan siap saji menjadi alternatif yang ditunjang oleh kondisi sosial ekonomi dan kepraktisan penyajian makanan dan waktu. ${ }^{4}$

Makanan cepat saji atau yang lebih dikenal dengan fast food mengandung asam jenuh yang tinggi dan omega 6 asam lemek, dan asupan omega 3 lemak yang kurang dan garam serta gula yang berlebihan, makanan tersebut dapat merusak jantung, ginjal dan lingkar pinggang. Namun hal ini semakin jelas terlihat bahwa fast food juga merusak sistem kekebalan tubuh. ${ }^{5}$

Pola makan yang tidak sehat pada remaja dapat berdampak pada masalah gizi. Masalah gizi yang dialami remaja umumnya seperti kelebihan berat badan/obesitas atau kekurangan zat gizi. Usia remaja memerlukan asupan gizi yang seimbang untuk masa pertumbuhannya ${ }^{6}$.

Menurut penelitian Nanik Keisianti, menunjukkan tingkat siswa SMAN 4 Surakarta yang sering mengkomsumsi fast food lebih banyak dibandingkan yang jarang mengomsumsi fast food. Hal ini memberikan berbagai alasan banyak yang membuat responden memilih mengomsumsi fast food antara lain dengan alasan malas makan dan alasan rasa enak.

Berdasarkan uraian diatas, peneliti ingin meneliti apakah terdapat hubungan antara komsumsi fast food dengan status gizi siswa di SMP Negeri 1 Limboto Barat.

\section{Metode Penelitian}

Penelitian ini merupakan peneitian suvey analitik dengan rancangan Cross Sectional Study dengan tujuan untuk mempelajari dinamika korelasi antara faktor-faktor risiko dengan efek, dengan cara pendekatan observasional atau pengumpulan data sekaligus pada waktu yang sama. Penelitian ini berlokasi di SMP Negeri 1 Limboto Barat. Terpilihnya lokasi ini karena akses dari sekolah ke restoran fast food sangat mudah terjangkau karena berada di tengah Kota Kabupaten Gorontalo, dimana pada keadaan ini mulai timbul kebiasaan atau gaya hidup makan bersama di restoran fast food.

Adapun sampel dalam penelitian ini adalah siswa (i) kelas VIII. Cara pengambilan sampel dalam penelitian ini adalah dengan cara Simple random sampling adalah teknik pengambilan sampel yang dilakukan secara acak sehingga setiap kasus atau elemen dalam populasi memiliki kesemptan yang sama besar untuk dipilih menjadi sampel penelitian. Diperoleh jumlah sampel yang akan di ambil dalam penelitian ini sebanyak 79 siswa.

\section{Hasil Penelitian}

\section{A. Analisis Univariat}

\section{Karakteristik Siswa Menurut Jenis Kelamin}

Tabel 1. Distribusi Jenis Kelamin Siswa SMP Negeri 1 Limboto Barat Kabupaten Gorontalo Tahun 2018

\begin{tabular}{lll}
\hline Jenis Kelamin & n & Persentase \\
\hline Laki-laki & 46 & 58,2 \\
Perempuan & 33 & 41,8 \\
\hline Jumlah & $\mathbf{7 9}$ & $\mathbf{1 0 0}$ \\
\hline Sumber : Data Primer 2018 \\
Berdasarkan tabel 1, menunjukan \\
bahwa dari 79 siswa terdapat jenis kelamin \\
laki-laki sebanyak 58,2\% dan perempuan \\
sebanyak 41,8\%.
\end{tabular}

\section{Status Gizi Siswa}

Tabel 2. Distribusi Status Gizi Siswa Siswa SMP Negeri 1 Limboto Barat Kabupaten Gorontalo Tahun 2018

\begin{tabular}{lll}
\hline Status Gizi & n & Persentase \\
\hline Obesitas & 3 & 3,8 \\
Overweight & 13 & 16,5 \\
Normal & 61 & 77,2 \\
Kurus & 2 & 2,5 \\
\hline Jumlah & $\mathbf{7 9}$ & $\mathbf{1 0 0}$ \\
\hline \multicolumn{2}{l}{ Sumber : Data } & Primer 2018
\end{tabular}


Berdasarkan tabel 2, menunjukan bahwa dari 79 siswa terdapat status gizi tertinggi yaitu normal sebanyak $77,2 \%$ dan yang terendah yaitu kurus sebanyak $2,5 \%$.

\section{Jenis Fast Food}

Tabel 3. Distribusi konsumsi Jenis Fast Food pada Siswa SMP Negeri 1 Limboto Barat Kabupaten Gorontalo Tahun 2018

\begin{tabular}{rcc}
\hline Jenis Fast Food & n & Persetase \\
\hline Tidak Normal & 61 & 77.2 \\
Normal & 18 & 22.8 \\
\hline Jumlah & $\mathbf{7 9}$ & $\mathbf{1 0 0}$
\end{tabular}

Sumber : Data Primer 2018

Berdasarkan tabel 3, menunjukan bahwa dari 79 siswa terdapat yang mengkonsumsi jenis fast food yang tidak normal sebanyak $77,2 \%$ dan normal sebanyak $22,8 \%$.

\section{Porsi Fast Food}

Tabel 4. Distribusi Porsi konsumsi Fast Food pada Siswa SMP Negeri 1 Limboto Barat Kabupaten Gorontalo Tahun 2018

\begin{tabular}{lcc}
\hline Porsi Fast Food & n & Persetase \\
\hline Tidak Normal & 24 & 30,4 \\
Normal & 55 & 69,6 \\
\hline Jumlah & $\mathbf{7 9}$ & $\mathbf{1 0 0}$ \\
\hline
\end{tabular}

Sumber : Data Primer 2018

\section{B. Analisis Bivariat}

1. Hubungan konsumsi Jenis Fast Food Dengan Status Gizi

Tabel 6. Hubungan konsumsi jenis Fast Food dengan Status Gizi Siswa SMP Negeri 1 Limboto Barat Kabupaten Gorontalo Tahun 2018

\begin{tabular}{|c|c|c|c|c|c|c|c|}
\hline \multirow{3}{*}{ Jenis Fast Food } & \multicolumn{4}{|c|}{ Status Gizi } & \multirow{2}{*}{\multicolumn{2}{|c|}{ Jumlah }} & \multirow{3}{*}{$\begin{array}{l}\mathbf{X}^{2} \\
\text { (p) }\end{array}$} \\
\hline & \multicolumn{2}{|c|}{ Tidak Normal } & \multicolumn{2}{|c|}{ Normal } & & & \\
\hline & $\mathrm{n}$ & Persen & $\mathrm{n}$ & Persen & $\mathrm{n}$ & Persen & \\
\hline Tidak Normal & 61 & 77,2 & 0 & 0 & 61 & 77,2 & 43,308 \\
\hline Normal & 7 & 8,9 & 11 & 13,9 & 18 & 22,8 & $(0,000)$ \\
\hline Jumlah & 68 & 86,1 & 11 & 13,9 & 79 & 100 & \\
\hline
\end{tabular}

Sumber : Data Primer, 2018

Berdasarkan tabel 6, menunjukkan bahwa dari 61 siswa yang tidak normal mengkonsumsi jenis Fast Food sebanyak $77,2 \%$ sedangkan dari 18 siswa yang
Berdasarkan tabel 4, menunjukan bahwa dari 79 siswa terdapat porsi konsumsi fast food tidak normal sebanyak $30,4 \%$ dan normal sebanyak $69,6 \%$

\section{Frekuensi konsumsi Fast Food}

Tabel 5. Distribusi Frekuensi konsumsi Fast Food pada Siswa SMP Negeri 1 Limboto Barat Kabupaten Gorontalo Tahun 2018

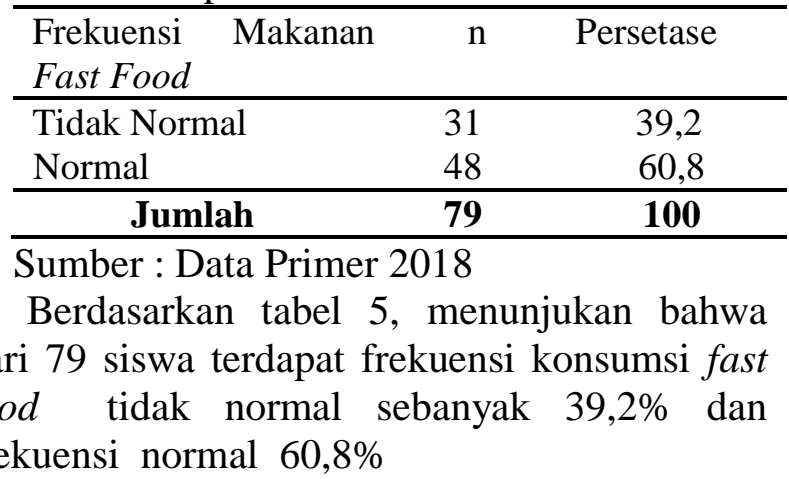


$(43,308)>\mathrm{X}^{2}$ tabel $(3,841)$ dan nilai $p$ $(0,000)<0,05$, ini berarti ada hubungan antara Jenis kosumsi Fast Food dengan status Gizi tidak normal di SMP Negeri 1
Limboto Barat Kabupaten Gorontalo Tahun 2018, dengan demikian hipotesis nol ditolak

\section{Hubungan konsumsi Porsi Fast Food Dengan Status Gizi}

Tabel 7. Hubungan konsumsi Porsi Fast Food Dengan Status Gizi Siswa SMP Negeri 1 Limboto Barat Kabupaten Gorontalo Tahun 2018

\begin{tabular}{|c|c|c|c|c|c|c|c|}
\hline \multirow{3}{*}{ Porsi Fast Food } & \multicolumn{4}{|c|}{$\begin{array}{r}\text { Status Gizi } \\
\end{array}$} & \multirow{2}{*}{\multicolumn{2}{|c|}{ Jumlah }} & \multirow{3}{*}{$\begin{array}{l}\mathbf{X}^{2} \\
(\mathbf{p})\end{array}$} \\
\hline & \multicolumn{2}{|c|}{ Tidak Normal } & \multicolumn{2}{|c|}{ Normal } & & & \\
\hline & $\mathrm{n}$ & Persen & $\mathrm{n}$ & Persen & $\mathrm{n}$ & Persen & \\
\hline Tidak Normal & 15 & 19,0 & 9 & 11,4 & 24 & 30,4 & 15,987 \\
\hline Normal & 53 & 67,1 & 2 & 2,5 & 55 & 69,6 & $(0,000)$ \\
\hline Jumlah & 68 & 86,1 & 11 & 13,9 & 79 & 100 & \\
\hline
\end{tabular}

Sumber : Data Primer, 2018

Berdasarkan tabel 7, menunjukkan bahwa dari 24 siswa yang tidak normal mengkonsumsi porsi Fast Food sebanyak $19,0 \%$ sedangkan dari 55 siswa yang normal mengkomsi Fast Food terdapat yang menderita sebanyak $67,1 \%$.

Berdasarkan hasil analisis statistik pada tabel $(3,841)$ dan nilai $p(0,000)<0,05$, ini berarti ada hubungan antara porsi kosumsi Fast Food dengan status Gizi tidak normal di SMP Negeri 1 Limboto Barat Kabupaten Gorontalo Tahun 2018, dengan demikian hipotesis nol ditolak

tabel 9 diperoleh nilai $\mathrm{X}^{2}$ hitung $(15,987)>\mathrm{X}^{2}$

Hubungan Frekuensi Makanan Fast Food Dengan Status Gizi

Tabel 8. Hubungan Porsi konsumsi Fast Food Dengan Status Gizi SMP Negeri 1 Limboto Barat Kabupaten Gorontalo Tahun 2018

\begin{tabular}{|c|c|c|c|c|c|c|c|}
\hline \multirow{3}{*}{$\begin{array}{l}\text { Frekuensi Fast } \\
\text { Food }\end{array}$} & \multicolumn{4}{|c|}{ Status Gizi } & \multirow{2}{*}{\multicolumn{2}{|c|}{ Jumlah }} & \multirow{3}{*}{$\begin{array}{l}\mathrm{X}^{2} \\
(\mathrm{p})\end{array}$} \\
\hline & \multicolumn{2}{|c|}{ Tidak Normal } & \multicolumn{2}{|c|}{ Normal } & & & \\
\hline & $\mathrm{n}$ & Persen & $\mathrm{n}$ & Persen & $\mathrm{n}$ & Persen & \\
\hline Tidak Normal & 27 & 34,2 & 4 & 5,1 & 31 & 39,2 & 0,044 \\
\hline Normal & 41 & 51,9 & 7 & 8,9 & 48 & 60,8 & $(0,833)$ \\
\hline Jumlah & 68 & 86,1 & 11 & 13,9 & 79 & $\overline{100}$ & \\
\hline
\end{tabular}

Sumber : Data Primer, 2018

Berdasarkan tabel 8, menunjukkan bahwa dari 31 siswa yang tidak normal frekuensi konsumsi Fast Food sebanyak 34,2\% sedangkan dari 48 siswa yang normal frekuensi konsumsi Fast Food terdapat yang menderita sebanyak 51,9\%.

Berdasarkan hasil analisis statistik pada tabel. 9 diperoleh nilai $X^{2}$ hitung $(0,044)<X^{2}$ tabel $(3,841)$ dan nilai $p(0,833)>0,05$, ini berarti tidak ada hubungan antara frekuensi kosumsi Fast Food dengan status Gizi tidak normal di SMP Negeri 1 Limboto Barat Kabupaten Gorontalo Tahun 2018, dengan demikian hipotesis nol diterima. 


\section{Pembahasan}

\section{Hubungan Jenis Makanan Fast Food Dengan Status Gizi}

Berdasarkan hasil analisis pada tabel 6 menunjukkan bahwa jenis makanan yang dikosumsi siswa terdapat yang lebih (tinggi kalori, karbohidrat, lemak jenuh). Dikarenakan banyak konsumsi siswa yang tidak terkontrol dengan hanya mementingkan enak tidaknya makanan yang dikonsumsi. Serta kurangnya konsumsi makanan tinggi serat seperti buah dan sayuran, dan banyaknya konsumsi makanan cepat oleh siswa sehingga menyebabkan overweight dan obesitas. Padahal seringnya makan fast food (makanan cepat saji), dan jarang mengkonsumsi sayur ataupun buah ${ }^{7}$.

Hal tersebut dapat mengakibatkan asupan makanan yang tidak sesuai dengan kebutuhan dan gizi seimbang akibatnya dapat menyebabkan gizi kurang atau gizi lebih ${ }^{8}$.

Secara umum dampak yang ditimbulkan akibat gizi lebih, adalah gangguan psiko-sosial, yang berakibat pada rasa rendah diri, depresi dan menarik diri dari lingkungan, dan gangguan pertumbuhan fisik, gangguan pernafasan, gangguan endokrin, obesitas yang menetap hingga dewasa dan penyakit degeneratif, yang berakibat pada timbulnya hipertensi, penyakit jantung koroner, diabetes mellitus dan lain sebagainya ${ }^{6}$.

\section{Hubungan Porsi Makanan Fast Food Dengan Status Gizi}

Berdasarkan hasil analisis pada tabel 7 menunjukkan bahwa porsi makan siswa uji menunjukkan bahwa ada hubungan secara bermakna antara porsi makan dengan status gizi. Hal ini dikarenakan konsumsi makan siswa bukan atas kebutuhan, yang tetapi akas keinginan dimana konsumsi makan siswa melebihi kebutuhan porsi dalam perharinya atau lebih dari $2475 \mathrm{kkal}$, sehingga peluang terjadinya overweight dan obesitas semakin besar ${ }^{9}$.

Asupan makanan yang melebihi kebutuhan tubuh akan menyebabkan kelebihan berat badan dan penyakit lain yang disebakan karena kelebihan zat gizi. Sebaliknya, asupan makanan kurang dari yang dibutuhkan akan menyebabkan tubuh menjadi kurus dan rentan terhadap penyakit. Kedua keadaan tersebut sama tidak baiknya, sehingga disebut gizi salah ${ }^{10}$.

3. Hubungan Frekuensi Makanan Fast Food Dengan Status Gizi

Berdasarkan hasil analisis pada tabel 8 menunjukkan bahwa frekuensi makan siswa terdapat hubungan secara bermakna antara frekuensi makan dengan status gizi. Hal ini sejalan dengan hasil penelitian yang Lusy bahwa ada hubungan yang signifikan antara frekuensi makan dengan kejadian obesitas ${ }^{11}$. Frekuensi makan adalah sejumlah pengulangan yang dilakukan dalam hal mengkonsumsi makanan baik kualitatif maupun kuantitatif yang terjadi secara berkelanjutan ${ }^{12}$.

Menurut Sjarif, bahwa memperoleh bahwa sebagian besar anak yang menderita obesitas/gizi lebih berasal dari orang tua dengan pendidikan tamat perguruan tinggi $(50,7 \%)$ dan terdapat hubungan signifikan antara pendidikan orang tua dengan kejadian obesitas pada anak $(\mathrm{p}<0,05)$, dan anak yang banyak melebihi dari 4 jenis fast food 12 kali berisiko terhadap kejadian obesitas dari pada anak yang tidak mengkonsumsi fast food. ${ }^{13,14}$.

\section{Kesimpulan}

1. Ditemukan ada hubungan antara Jenis kosumsi Fast Food dengan status Gizi tidak normal di SMP Negeri 1 Limboto Barat Kabupaten Gorontalo Tahun 2018 diperoleh nilai $\mathrm{X}^{2}$ hitung $(43,308)>\mathrm{X}^{2}$ tabel $(3,841)$ dan nilai $p(0,000)<0,05$, dengan demikian hipotesis nol ditolak. 
2. Ditemukan ada hubungan antara porsi kosumsi Fast Food dengan status Gizi tidak normal di SMP Negeri 1 Limboto Barat Kabupaten Gorontalo Tahun 2018, diperoleh nilai $\mathrm{X}^{2}$ hitung $(13,844)>\mathrm{X}^{2}$ tabel $(3,841)$ dan nilai $p(0,000)<0,05$ dengan demikian hipotesis nol ditolak.

3. Ditemukan tidak ada hubungan antara frekuensi kosumsi Fast Food dengan status Gizi tidak normal di SMP Negeri 1 Limboto Barat Kabupaten Gorontalo Tahun 2018, diperoleh nilai $\mathrm{X}^{2}$ hitung $(0,044)>\mathrm{X}^{2}$ tabel $(3,841)$ dan nilai $p(0,833)>0,05$ dengan demikian hipotesis nol diterima

\section{Saran}

1. Diharapkan kepada siswa agar lebih membatasi jenis kosumsi fast food dengan mengetahui bahwa dari komsumsi fast food yang berlebihan tidaklah baik untuk kesehatan, dan lebih cerdas dalam memilih makanan yang akan dikonsumsi.

2. Diharapkan kepada orang tua siswa agar lebih inisiatif dalam memantau konsumsi makan anaknya, baik dalam lingkungan sekolah maupun di rumah.

3. Diharapkan kepada peneliti selanjutnya agar memperhatikan penelitian ini agar menjadi informasi pendukung dalam penelitiannya.

\section{Daftar Pustaka}

1. Adriani, Merryana dan Bambang Wirjamadi. 2012. Peranan Gizi Dalam Siklus Kehidupan. Jakarta. Prenda Media.

2. WHO. 2014. Global Strategy on Diet, Physical Activity and Health

3. Departemen Gizi dan Kesehatan Masyarakat, Gizi dan Kesehatan Masyarakat. Jakarta : PT. Rajagafrindo Persada, 2011.

4. Puspasari, Andri, 2017. Hubungan pendapatan keluarga dengan status gizi. Tersedia di http e-Jurnal Pustaka Kesehatan.
5. Imam, Sukiman, 2012. Obesitas Konsekuensi Pencegahan dan Pengobatan. Makalah Penetapan Guru Besar Fakultas Kedokteran Bidang Bidang Ilmu Patologi Klinik Universitas Sumatera Utara, Medan.

6. Manurung, Nelly. Pengaruh Karakteristik Remaja, Genetik, Pendapatan Keluarga, Pendidikan Ibu, Pola Makan, aktivitas Fisik Terhadap Kejadian Obesitas di SMU Rk Tri Sakti Medan, 2008. Tesis. Universitas Sumatera Utara, 2009.

7. Supriasa. I. D. N. Bachyar Bakri dan Ibnu Fajar. 2012. Jakarta: EGC

8. Yudesti, Ira dan Nanang Prayinto. 2013. Perbedaan Status Gizi Anak SD Kelas IV dan V di SD Unggulan (06 Pagi Makassar) dan SD Non Unggulan (09 Pagi Pasar Pinang Ranti) Kecamatan Makassar Jakarta Timur Tahun 2012. Jurnal Ilmiah Kesehatan. Vol.5 (1) Januari, p.1-5

9. Khomsan, A. 2003. Pangan dan Gizi untuk Kesehatan. PT Raya Grafindo Persada. Jakarta.

10. Sukamadinata, 2005. Kegemukan, Obesitas dan Degeneratif : Epidemiologi dan Strategi Penanggulangan. Dalam Widya Karya Nasional Pangan dan Gizi VI. Jakarta, LIPI.

11. Lusy Nurdiani Putri. "Hubungan Konsumsi Fast Food Dengan Status Gizi Remaja Di SMP 6 Makassar Tahun 2014”. Skripsi. Fakultas Ilmu Kesehatan Universitas Islam Alauddin Makassar.

12. Purtiantini. 2010. "Hubungan Pengetahuan dan Sikap Mengenai Pemilihan Makanan Jajanan Dengan Perilaku Anak Memilih Makanan Di SDIT Muhammadiyah Al Kautsar Gumpang Kartasura:. Skripsi. Fakultas Ilmu Kesehatan Universitas Muhammadiya Surakarta.

13. Sjarif, 2012. Pengkajian Status Gizi : Studi Epidemiologi. Fakultas Kedokteran Universitas Indonesia, Jakarta.

14. Notoadmodjo. Soekodjo. 2010. Teori dan Aplikasi Promosi Kesehatan Masyarakat. Jakarta: PT Rincka Cipta. 